\title{
Delivery of Matrix Metalloproteinase-1 Attenuates Established Liver Fibrosis in the Rat
}

\author{
YUJI IIMURO,* TOSHIHIRO NISHIO,* TAISUKE MORIMOTO,* TAKASHI NITTA,* \\ BRANKO STEFANOVIC, ${ }^{\dagger}$ SUNG KYU CHOI, ${ }^{\ddagger}$ DAVID A. BRENNER, ${ }^{\dagger}$ and YOSHIO YAMAOKA* \\ *Department of Gastroenterological Surgery, Kyoto University Graduate School of Medicine, Kyoto, Japan; and ${ }^{\star D}$ Departments of Medicine, \\ Biochemistry, and Biophysics, University of North Carolina at Chapel Hill, Chapel Hill, North Carolina
}

Background \& Aims: During hepatic fibrogenesis, the hepatic extracellular matrix changes to fibrillar collagens types I and III, and cirrhosis is believed to produce an irreversible scar. In this study, we investigated whether gene delivery of human matrix metalloproteinase-1, which degrades collagens types I and type III, would attenuate established hepatic fibrosis in the rat, induced by either thioacetamide or bile duct ligation. Methods: Hepatic fibrosis induced by thioacetamide for 7 weeks was persistent for at least $\mathbf{2}$ months, even after discontinuation of the treatment. The rats were infected once with a recombinant adenovirus, Ad5MMP-1, into which human pro-human matrix metalloproteinase-1 complementary DNA was packaged, or with a control adenovirus, Ad5LacZ. Results: In Ad5MMP-1-infected, but not in Ad5LacZ-infected, rats, the fibrosis was dramatically attenuated at $\mathbf{2}$ weeks after the infection. It is interesting to note that the number of activated hepatic stellate cells was also decreased in Ad5MMP-1-infected rats. Moreover, disorganization of the hepatic trabecula, heterogeneity in the size of hepatocytes, and increased dried liver weight were observed only in Ad5MMP-1treated rats, suggesting that human matrix metalloproteinase-1 stimulated hepatocyte proliferation, which was confirmed by bromodeoxyuridine staining. After 4 weeks, the proliferative effect of human matrix metalloproteinase-1 almost disappeared, but the hepatic fibrosis remained attenuated, whereas the fibrosis in Ad5LacZ-treated rats persisted. Furthermore, the administration of Ad5MMP-1, but not Ad5LacZ, decreased type I collagen and generated a small collagen fragment in hepatic fibrosis induced by bile duct ligation. Conclusions: Our findings show that transient human matrix metalloproteinase-1 overexpression in the liver effectively attenuates established fibrosis and induces hepatocyte proliferation.

T epatic fibrogenesis is characterized by increased 1 deposition of extracellular matrix (ECM), such as fibrillar collagens type I and type III. ${ }^{1,2}$ The major source of these newly synthesized collagens is hepatic stellate cells (HSCs) activated by a variety of fibrogenic stimuli. ${ }^{3}$
The key enzymes in the degradation of fibrillar collagens are matrix metalloproteinase (MMP)-1 in humans and MMP-13 in rats. ${ }^{4,5}$ However, during fibrogenesis, the expression of MMP-1 or MMP-13 is very limited, whereas that of MMP-2 increases. ${ }^{6-8}$ Moreover, fibrotic livers also have high expression of the tissue inhibitors of metalloproteinase (TIMPs), including TIMP-1 and TIMP-2.9,10 Thus, there is a combination of low expression of interstitial collagenases and high TIMPs that prevents degradation of the fibrillar collagens.

Another important factor in hepatic fibrogenesis is a balance between urokinase plasminogen activator (uPA) and plasminogen activator inhibitors. ${ }^{11}$ Plasmin, which is generated by uPA, degrades ECM both directly and indirectly by activation of MMPs. Plasminogen activator inhibitor-1 expression is increased in activated HSCs and in experimental cirrhotic livers concomitant with increased expression of uPA and its receptor, whereas plasminogen activator inhibitor-1 messenger RNA levels are unchanged in mild fibrosis. ${ }^{12}$ Indeed, the plasma concentration of plasminogen activator inhibitor-1 is increased in patients with chronic liver diseases. ${ }^{13}$

Cirrhosis is generally considered to be stable even after the removal of the fibrotic stimuli, whereas mild liver fibrosis is sometimes reversible. ${ }^{14}$ Several approaches have been reported in experimental animals to prevent the progression of liver fibrosis ${ }^{15-21}$ or to reverse advanced liver fibrosis with hepatocyte growth factor. ${ }^{22,23}$ However, to date, no effective therapy for hepatic fibrosis has been developed.

Abbreviations used in this paper: Ad5, adenovirus type 5; APMA, p-aminophenylmercuric acetate; BrdU, bromodeoxyuridine; ECM, extracellular matrix; HSC, hepatic stellate cell; MMP, matrix metalloproteinase; PAGE, polyacrylamide gel electrophoresis; pfu, plaque-forming unit; SDS, sodium dodecyl sulfate; SMA, smooth muscle actin; TAA, thioacetamide; TIMP, tissue inhibitor of metalloproteinase; uPA, urokinase plasminogen activator.

(C) 2003 by the American Gastroenterological Association $0016-5085 / 03 / \$ 35.00$ doi:10.1053/gast.2003.50063 
Our hypothesis is that failure to resolve the fibrous scar results from the imbalance between too few interstitial collagenases (MMP-1 or MMP-13) and too much ECM and too many TIMPs. Furthermore, we propose that the aberrant matrix of the fibrous scar maintains the HSC in the activated state. We tested this hypothesis by transiently changing the balance by using gene therapy to deliver MMP-1 in a rat model of persistent liver fibrosis.

\section{Materials and Methods}

\section{Construction of the Recombinant Adenovirus Ad5MMP-1}

The recombinant replication-deficient adenovirus Ad5MMP-1 was constructed by the methods of Bett et al. ${ }^{24}$ In brief, plasmid pRc/CMV-pro-MMP-1, which contains a human pro-MMP-1 complementary DNA, ${ }^{25}$ was subcloned into the SalI/HindIII site of the pACCMV.PLPASR $(+)$ plasmid to construct the plasmid pACCMV/MMP-1, in which proMMP-1 is driven by the cytomegalovirus promoter/enhancer. The recombinant adenovirus was then constructed by cotransfection of the 293 embryonic human kidney cell line with the pACCMV/MMP-1 plasmid plus the purified fragment of ClaIdigested DNA from E1-deleted adenovirus type 5 (Ad5). The human pro-MMP-1 sequence packaged into the recombinant Ad5 virus (Ad5MMP-1) was confirmed by polymerase chain reaction and by Western blotting. Ad5MMP-1 was grown in 293 cells and purified by banding twice on $\mathrm{CsCl}$ gradients. Viral titers were determined by optical densitometry (particles per milliliter) and by plaque assay, and recombinant virus was then stored in $10 \%$ (vol $/ \mathrm{vol}$ ) glycerol at $-20^{\circ} \mathrm{C}$. Ad5LacZ, which contains the Escherichia coli $\beta$-galactosidase gene, was also grown and purified as described previously and used as a control virus.

\section{Western Blot Analysis}

Culture medium of Rat-2 fibroblasts infected with Ad5MMP-1 (multiplicity of infection, 25) for 48 hours was collected, concentrated with Centriplus (Amicon Inc., Beverly, $\mathrm{MA}$ ), and stored at $-80^{\circ} \mathrm{C}$ for later analysis. To confirm that expressed human pro-MMP-1 was correctly activated by its activator, some of the culture medium was incubated with p-aminophenylmercuric acetate (APMA; $1 \mathrm{mmol} / \mathrm{L}$ ) at $37^{\circ} \mathrm{C}$ for 4 hours and used for Western blot analysis. Liver tissues from rats infected with Ad5MMP-1 $\left(5 \times 10^{9}\right.$ plaque-forming units [pfu]) for 72 hours were homogenized in lysis buffer (10 $\mathrm{mmol} / \mathrm{L}$ of HEPES [pH 7.9], $0.42 \mathrm{~mol} / \mathrm{L}$ of $\mathrm{NaCl}, 1.5 \mathrm{mmol} / \mathrm{L}$ of $\mathrm{MgCl}_{2}, 0.5 \mathrm{mmol} / \mathrm{L}$ of dithiothreitol, $0.5 \%$ Nonident P- 40 , and $25 \%$ glycerol) with protease inhibitors at $4^{\circ} \mathrm{C}$, followed by rotating the tubes for 30 minutes at $4^{\circ} \mathrm{C}$. After centrifugation, cleared tissue lysates were collected and stored at $-80^{\circ} \mathrm{C}$ for later analysis. Lysate containing $20 \mu \mathrm{g}$ of protein was separated by electrophoresis on $10 \%$ acrylamide sodium dodecyl sulfate (SDS) gels and transferred to polyvinylidene difluoride mem- branes as described previously. ${ }^{26}$ Equal loading was confirmed by Ponceau $\mathrm{S}$ staining. Human MMP-1 was detected by using rabbit anti-MMP-1 antibody (Chemicon International Inc., Temecula, CA). Blots were blocked in blocking buffer (5\% nonfat dry milk in PBST [phosphate-buffered saline containing $0.05 \%$ Tween 20]) for 1 hour, incubated overnight at $4^{\circ} \mathrm{C}$ in primary antibody, diluted 1:1000 in blocking buffer, and then diluted 1 hour with horseradish peroxidase-conjugated goat anti-rabbit secondary antibody (Amersham Corp., Arlington Heights, IL) diluted 1:1000 in blocking buffer. Proteins were detected with enhanced chemiluminescence detection reagents (Amersham Corp.).

\section{Enzymatic Activity of Matrix Metalloproteinase-1 In Vitro and In Vivo}

Human MMP-1, which was expressed in vitro, was tested for its enzymatic activity against type I collagen at $37^{\circ} \mathrm{C}$. Collagen type I derived from rat tail $(30 \mu \mathrm{g} ; \mathrm{BD}$ Biosciences, Bedford, MA) was incubated for 12 hours with supernatant of Rat-2 fibroblasts infected with Ad5MMP-1 or Ad5LacZ. ${ }^{27}$ Reactions were stopped by adding SDS-polyacrylamide gel electrophoresis (PAGE) loading buffer with 20 $\mathrm{mmol} / \mathrm{L}$ of EDTA ( $\mathrm{pH} 8.0$ ), and the products were analyzed on SDS-PAGE stained with Coomassie stain (Bio-Rad Laboratories, Hercules, CA). Collagen was then examined for digestion into smaller fragments. In this study, APMA (1 mmol/L) was added to some supernatants to convert pro-MMP-1 to its active form, and $20 \mathrm{mmol} / \mathrm{L}$ of EDTA ( $\mathrm{pH}$ 8.0) was added to some reactions in advance to suppress MMP-1 activity.

The enzymatic activity of human MMP-1 in vivo was accessed in a liver fibrosis model established by bile duct ligation. With male Sprague-Dawley rats (250 g body weight), the bile duct was surgically ligated under anesthesia. ${ }^{28}$ Ten days later, the rats were injected through the tail vein with $5 \times 10^{9}$ pfu of Ad5MMP-1 or control virus (Ad5LacZ). Livers were harvested 2 days after the virus injection, and proteins were extracted with $6 \mathrm{~mol} / \mathrm{L}$ of guanidine $\mathrm{HCl}$ for 3 days. Proteins were then dialyzed against phosphate-buffered saline (PBS) for $2 \mathrm{~h}$, and then SDS was added to a final concentration of $1 \%$ and protein concentrations were determined by Bradford assay. A total of $50 \mu \mathrm{g}$ of protein was run under reducing conditions on $7.5 \%$ gel, and Western blot was performed with anti-collagen $\alpha 1(\mathrm{I})$ antibody (dilution 1:1000; Biodesign International, Saco, ME).

\section{Induction of Liver Fibrosis With Thioacetamide in the Rat}

Thioacetamide (TAA) (200 mg/kg body weight) was injected intraperitoneally 3 times a week into male SpragueDawley rats (100 g body weight) for 4 or 7 weeks. The administration of TAA was stopped before the therapy to prevent any confusion with drug delivery or metabolism, which would be of concern if we were giving the fibrogenic agent at the same time as the therapy. After withdrawal of TAA treatment of 7 weeks, hepatic fibrosis persisted at least 
for 2 months; this is similar to the results of a previous report. ${ }^{29,30}$

\section{Adenoviral Infection and Tissue Sampling}

Ad5MMP-1 or Ad5LacZ was stored in $10 \%$ glycerol and was then twice dialyzed against a solution containing 10 $\mathrm{mmol} / \mathrm{L}$ of Tris ( $\mathrm{pH} 8.0$ ), $1 \mathrm{mmol} / \mathrm{L}$ of $\mathrm{MgCl}_{2}$, and 140 $\mathrm{mmol} / \mathrm{L}$ of $\mathrm{NaCl}$ for 2 hours just before use. One week after finishing the treatment of TAA, rats were infected once with recombinant adenovirus $\left(5 \times 10^{9}\right.$ pfu per rat, $\left.0.5 \mathrm{~mL}\right)$ by intravenous injection through tail veins. At 2 or 4 weeks after the adenoviral infection, rats were killed, and liver tissues were examined. Animals were injected with bromodeoxyuridine (BrdU) (100 mg/kg; Sigma Chemical Co., St. Louis, MO) and killed 1 hour later. Blood samples were collected by puncture of the abdominal aorta, and serum was stored at $-80^{\circ} \mathrm{C}$ until analysis. Samples of the liver were snap-frozen in liquid nitrogen or were fixed in $10 \%$ buffered formalin for subsequent histological analysis. The efficiency of adenoviral gene transfer to the liver in vivo was examined by $\mathrm{X}$-gal staining ${ }^{31}$ of the liver infected with Ad5LacZ $\left(5 \times 10^{9}\right.$ pfu per rat); more than $90 \%$ of hepatocytes and approximately $25 \%$ of nonparenchymal cells were positive for $\beta$-galactosidase (data not shown).

\section{Histology and Immunohistochemistry}

The liver specimens were fixed overnight in $10 \%$ phosphate-buffered formaldehyde, embedded in paraffin, and stained with $\mathrm{H} \& \mathrm{E}$ and Masson's trichrome. For immunohistochemical studies, sections were deparaffinized in xylene and rehydrated in alcohol. A DAKO Envision system (DAKO Corp., Carpinteria, CA) was used for $\alpha$-smooth muscle actin $(\alpha-S M A)$, desmin, and BrdU immunostaining. After blocking of endogenous peroxidase with peroxidase-blocking agent, sections were incubated with mouse anti- $\alpha$-SMA (1:200; DAKO) or mouse anti-desmin (DAKO) for 10 minutes at $25^{\circ} \mathrm{C}$. After two 3-minute washes in PBS, sections were incubated with labeled polymer (peroxidase-labeled polymer conjugated to goat anti-rabbit and goat anti-mouse immunoglobulins) for 10 minutes at $25^{\circ} \mathrm{C}$. Sections were then washed twice with PBS, incubated with 3,3-diaminobenzidine substrate chromogen for 8 minutes, washed with distilled water, incubated with 3,3diaminobenzidine enhancer (Innovex Biosciences, Richmond, CA) for 5 minutes, and washed with distilled water before counterstaining with hematoxylin. For BrdU assay, deparaffinized sections were incubated in $4 \mathrm{~N} \mathrm{HCl}$ for 20 minutes at $37^{\circ} \mathrm{C}$ and washed several times with distilled water and $1 \times$ PBS. After blocking of endogenous peroxidase with peroxidaseblocking agent, sections were incubated with mouse monoclonal anti-BrdU antibody (1:200 in PBS containing 5\% bovine serum albumin; Sigma Chemical Co.) for $10 \mathrm{~min}$ at $25^{\circ} \mathrm{C}$. The procedure was the same for $\alpha$-SMA and desmin staining. Semiquantitative image analysis was also performed for the $\alpha$-SMA-positive area in the liver tissues according to the method described below, because to count $\alpha$-SMA-positive cells was sometimes difficult even under high-power fields.

\section{Sirius Red Staining and Image Analysis}

To semiquantitatively determine collagen contents in liver tissues, deparaffinized liver sections were incubated for 15 minutes in a solution of saturated picric acid containing $0.1 \%$ Fast Green FCF, followed by incubation for 40 minutes in $0.1 \%$ Sirius red in saturated picric acid. ${ }^{32}$ Stained slides were washed in running distilled water, dehydrated, mounted, and examined by light microscopy. Microscopic pictures of the stained liver specimens were taken $(40 \times)$, and positive signals were analyzed with the freeware image analysis program $\mathrm{NIH}$ Image 1.61 (http://rsb.info.nih.gov/nih-image/index.html). By using the NIH Image program, the signals from the gray scale were quantified, and the mean area of fibrosis was calculated as an average percentage for 5 fields $(40 \times)$ from each animal.

\section{Quantification of Hydroxyproline in Liver Tissues}

The rat liver tissues were stored at $-80^{\circ} \mathrm{C}$ until use. Each tissue was thawed on ice and minced manually by using a razor blade and then pulverized to fine powder in liquid nitrogen by a Spex Freezer Mill (SPEX CertiPrep, Metuchen, NJ). The samples were washed with cold PBS several times and then with cold distilled water and lyophilized. The dried samples were hydrolyzed with $6 \mathrm{~N} \mathrm{HCl}$ in vacuo, after flushing with nitrogen, for 22 hours at $110^{\circ} \mathrm{C}$. The hydrolysates were dried in a speed vacuum concentrator, and the residues were dissolved in distilled water. The hydrolysates were filtered through $0.22-\mu \mathrm{m}$ Millipore filters. The hydroxyproline contents in the rat liver samples were determined by a highperformance liquid chromatography method. ${ }^{33}$

\section{Measurement of Dry Liver Weight}

Whole liver weight was measured in each animal at death; a part of the liver was collected, and its wet weight was determined. The rest of the liver was used for other assays. The liver tissue was dried at $80^{\circ} \mathrm{C}$ for 72 hours, and its dry weight was determined. Dry whole liver weight was calculated as (wet whole liver weight $) /($ wet liver tissue weight $) \times($ dry liver tissue weight).

\section{Liver Function Test}

Blood samples were collected from each animal by aortic puncture before killing. Serum was stored at $-80^{\circ} \mathrm{C}$ until measurement of alanine aminotransferase (ALT), bilirubin, and albumin by automatic analysis.

\section{Statistics}

Analysis of variance and Dunnett's post hoc test were used for determination of statistical significance. Significance was defined as a $P$ value of $<0.05$. 
A

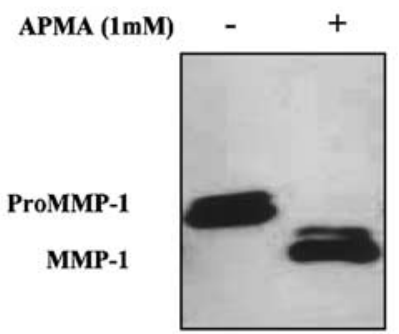

C

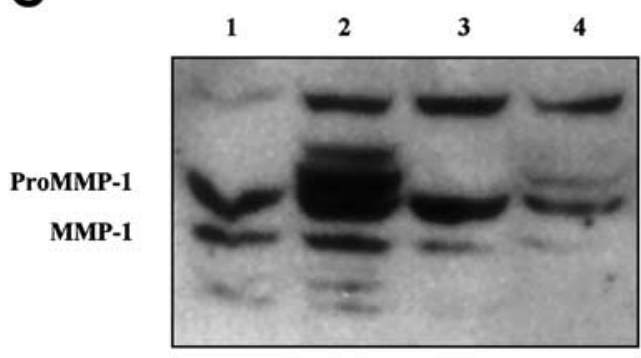

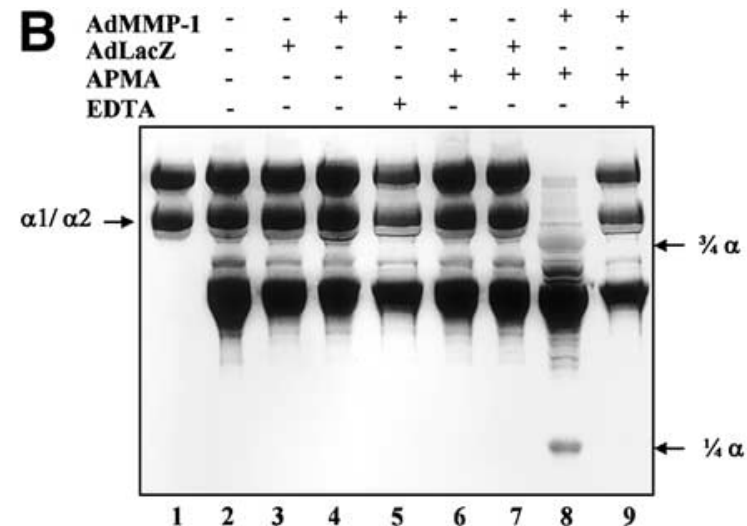

D

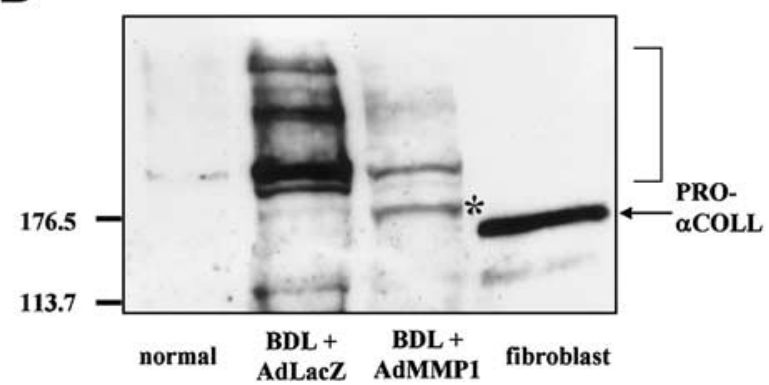

Figure 1. Expression of human pro-MMP-1 and MMP-1 in vitro and in vivo. (A) Culture medium was collected from Rat-2 fibroblasts 48 hours after infection with Ad5MMP-1, as described in Methods. Expression of human pro-MMP-1 protein in the medium was assessed by Western blotting with anti-human MMP-1 antibody, which detects both pro-MMP-1 and MMP-1. In addition to human pro-MMP-1 (51 kilodaltons), an active form of human MMP-1 (41 kilodaltons) was detected after incubation with p-aminophenylmercuric acetate (APMA; $1 \mathrm{mmol} / \mathrm{L}$ ) at $37^{\circ} \mathrm{C}$ for $4 \mathrm{hours}$. (B) Type I collagen $(30 \mu \mathrm{g})$ was incubated for 12 hours at $37^{\circ} \mathrm{C}$ with culture medium of Rat-2 fibroblasts infected with Ad5MMP-1 or Ad5LacZ. The products were separated on SDS-PAGE and stained with Coomassie blue. APMA was added to some incubation mixtures to activate MMP-1, and EDTA was used to block MMP-1 activity. Lane 1 was the original substrate, collagen type I. (C) Male Sprague-Dawley rats (250-280 g) were infected with Ad5MMP-1 ( $5 \times 10^{9}$ pfu per rat intravenously) for 72 hours, and liver tissues were collected. Western blotting for human pro-MMP-1 and MMP-1 was performed by using liver homogenate as described in Methods. Lanes 1-4 were liver homogenate collected from 4 individual rats infected with Ad5MMP-1. (D) Bile ducts were ligated in rats, and after 10 days the rats were injected through the tail veins with $5 \times 10^{9}$ pfu of Ad5MMP-1 or control virus (Ad5LacZ). Livers were harvested 2 days after the virus injection, and proteins were prepared as described in Methods. Western blot was performed with anti-collagen $\alpha 1(\mathrm{I})$ antibody. Lane 1, normal rat liver; lane 2, bile duct-ligated liver with control virus; lane 3, bile duct-ligated liver with Ad5MMP-1; lane 4, medium of rat fibroblasts. Migration of pro-collagen $\alpha 1(\mathrm{I})$ is indicated by an arrow. Higher-molecular-weight collagen species, which represent cross-linked type I collagen, are indicated by the bracket, and a degradation product of type I collagen is indicated by an asterisk (lane 3). Representative data of 3 repeated experiments are shown.

\section{Results}

\section{Assessment of a Recombinant Adenovirus Expressing Human Pro-MMP-1}

Rat-2 fibroblasts were infected with the Ad5MMP-1 adenovirus (multiplicity of infection, 20), and then the culture medium was collected after 48 hours and prepared for Western blot analysis. By using an anti-human MMP-1 antibody, which detects both pro-MMP-1 and MMP-1, the expressed human proMMP-1 (51 kilodaltons) was identified in the culture medium (Figure $1 A$, left lane). After incubation with APMA ( $1 \mathrm{mmol} / \mathrm{L})$ at $37^{\circ} \mathrm{C}$ for 4 hours, the pro-MMP- 1 band shifted lower (41 kilodaltons), which was consistent with the active form of human MMP-1 (Figure $1 A$, right lane). Enzymatic activity of expressed human MMP-1 in vitro was shown by its ability to digest type I collagen into smaller fragments (Figure $1 B$, lane 8). Adding EDTA to the incubation mixtures clearly blocked the enzymatic activity (Figure $1 B$, lane 9), consistent with this enzyme's being a metalloproteinase. Western blot analysis with liver tissue homogenates showed that the delivery of human pro-MMP-1 complementary DNA by Ad5MMP-1 $\left(5 \times 10^{9}\right.$ pfu per rat intravenously) successfully expressed pro-MMP-1 in all livers infected with Ad5MMP-1 (Figure 1C, lanes 1-4). Moreover, the active form of MMP-1 (41 kilodaltons) was also detected in this assay, indicating that the expressed pro-MMP-1 protein was gradually converted to the active form in vivo (Figure $1 C$ ). These 2 bands were not detected in control or Ad5LacZ-infected rats (data not shown). The enzymatic 
activity of MMP-1 in vivo was accessed in a bile duct ligation model of hepatic fibrosis by Western blot with anti-collagen $\alpha 1(\mathrm{I})$ antibody, as described in Methods. Higher-molecular-weight collagen species (indicated by the bracket in Figure 1D), which represent cross-linked type I collagen, were detected in the fibrotic liver treated with the control adenovirus (AdLacZ), whereas a very small amount of these collagen species was observed in normal rat liver. However, in the fibrotic liver infected with Ad5MMP-1, these cross-linked type I collagen species were dramatically decreased, and a degradation product of type I collagen (Figure $1 D$, asterisk) was detected. Histologically, the short-term bile duct ligation produced, as expected, equal bile duct proliferation but minimal fibrosis in both Ad5MMP-1- and Ad5LacZ-infected animals (data not shown). These data indicated that pro-MMP-1 transferred in vivo was activated and degraded cross-linked type I collagen in fibrotic liver.

\section{Thioacetamide Treatment Established Persistent Hepatic Fibrosis in the Rat}

After treatment with TAA $(200 \mathrm{mg} / \mathrm{kg}$ body weight) for 4 weeks, mild fibrosis was observed in the liver, and the fibrosis persisted until the end of this experiment ( 5 weeks after the removal of TAA treatment) (Figure $2 A$ and $B$ ). TAA treatment for 7 weeks induced more advanced hepatic fibrosis, and so-called regenerating lobules were often observed (Figure $2 C$, asterisk). The fibrosis observed in the 7-week TAA model was almost unchanged until the end of this study (Figure 2D). We assessed 6 animals in each experiment and obtained similar results in each animal. These results and those of previous studies ${ }^{29,30}$ show that TAA-induced liver fibrosis is a clinically relevant model for the treatment of stable fibrosis.

\section{Histological Changes of Liver Fibrosis After the Adenoviral Infection}

One week after their last treatment, TAA-treated rats were infected with Ad5MMP-1 or Ad5LacZ $(5 \times$ $10^{9}$ pfu per rat). Histological change of the liver was examined at 2 and 4 weeks after the infection. The control Ad5LacZ had no obvious effect on the established liver fibrosis, which received TAA treatment for 7 weeks (Figure $3 A$ and $B$ ). After the Ad5MMP-1 infection, fibrosis was significantly attenuated by 2 weeks and remained attenuated by 4 weeks, as indicated by Masson's trichrome staining (Figure $3 C$ and $D$ ). In the rats treated with TAA for 4 weeks, mild hepatic fibrosis in the interlobular spaces was observed, and the fibrosis almost disappeared at 2 weeks after the infection with
Ad5MMP-1, but not with Ad5LacZ. The fibrosis remained resolved even at 4 weeks (data not shown).

\section{Quantitative Analysis of Liver Fibrosis After the Adenoviral Infection}

Semiquantitative analysis of liver fibrosis was performed by Sirius red staining and image analysis. Red color area observed in the liver after TAA treatment for 7 weeks (Figure $4 A$ ) was obviously decreased in Ad5MMP-1-infected rats at 2 weeks (Figure $4 B$ ), whereas Ad5LacZ did not affect the fibrosis (Figure $4 C$ ). Image analysis showed that the percentage of fibrosis area in the liver was dramatically decreased by MMP-1 expression (Figure 4D). Quantification of hydroxyproline in the liver by high-performance liquid chromatography confirmed that MMP-1 expression in the liver significantly attenuated collagen deposition in this model (Figure $4 E$ ). Although the decrease in hydroxyproline content was less striking than that observed with Sirius red staining, the hydroxyproline assay measures undegraded and degraded collagen, and similar discrepancies between these types of measurements have been previously described. ${ }^{22,34,35}$

\section{Overexpression of MMP-1 Decreased the Number of Activated Hepatic Stellate Cells}

After TAA treatment for 7 weeks, the area of $\alpha$-SMA-positive cells (a marker of activated HSCs) in the liver markedly increased (Figure $5 A$ ), especially in the interlobular space, where deposition of fibrillar collagens was observed (Figure 4A). In Ad5MMP-1-infected rats, the $\alpha$-SMA-positive area dramatically decreased at 2 weeks (Figure 5B), whereas infection with Ad5LacZ had no effect (Figure $5 C$ ). A significant decrease in the $\alpha$-SMA-positive area was observed only in Ad5MMP-1-infected animals (Figure $5 G$ ). This result indicated that degradation of fibrillar collagens because of MMP-1 overexpression in the liver leads to a decrease in the number of activated HSCs. To further examine whether activated HSCs disappeared or were transformed to quiescent HSCs, liver tissues underwent an immunostaining of desmin, a marker of all HSCs. The number of desmin-positive cells in the liver was also dramatically decreased in Ad5MMP-1-infected rats (Figure $5 E)$ compared with that in uninfected and Ad5LacZ-infected rats (Figure $5 D$ and $F$ ).

\section{MMP-1 Expression in the Liver Induced Hepatocyte Proliferation}

Histological analysis of the TAA-treated liver tissues with $\mathrm{H} \& \mathrm{E}$ staining showed disarrangement of the hepatic trabecula and heterogeneity in the size of hepatocytes without obvious inflammatory changes only in Ad5MMP-1-infected rats at 2 weeks (Figure $6 B$, 

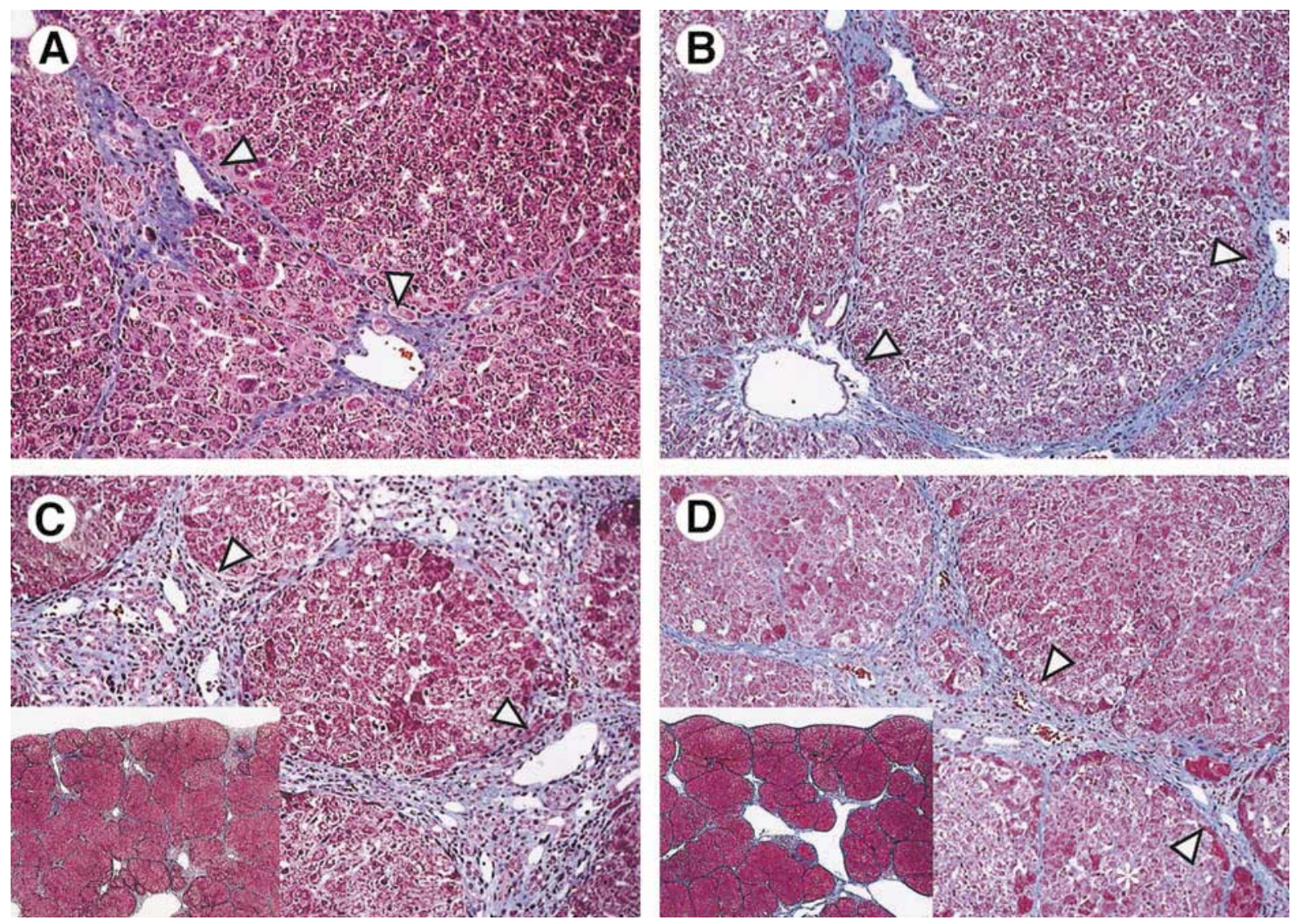

Figure 2.
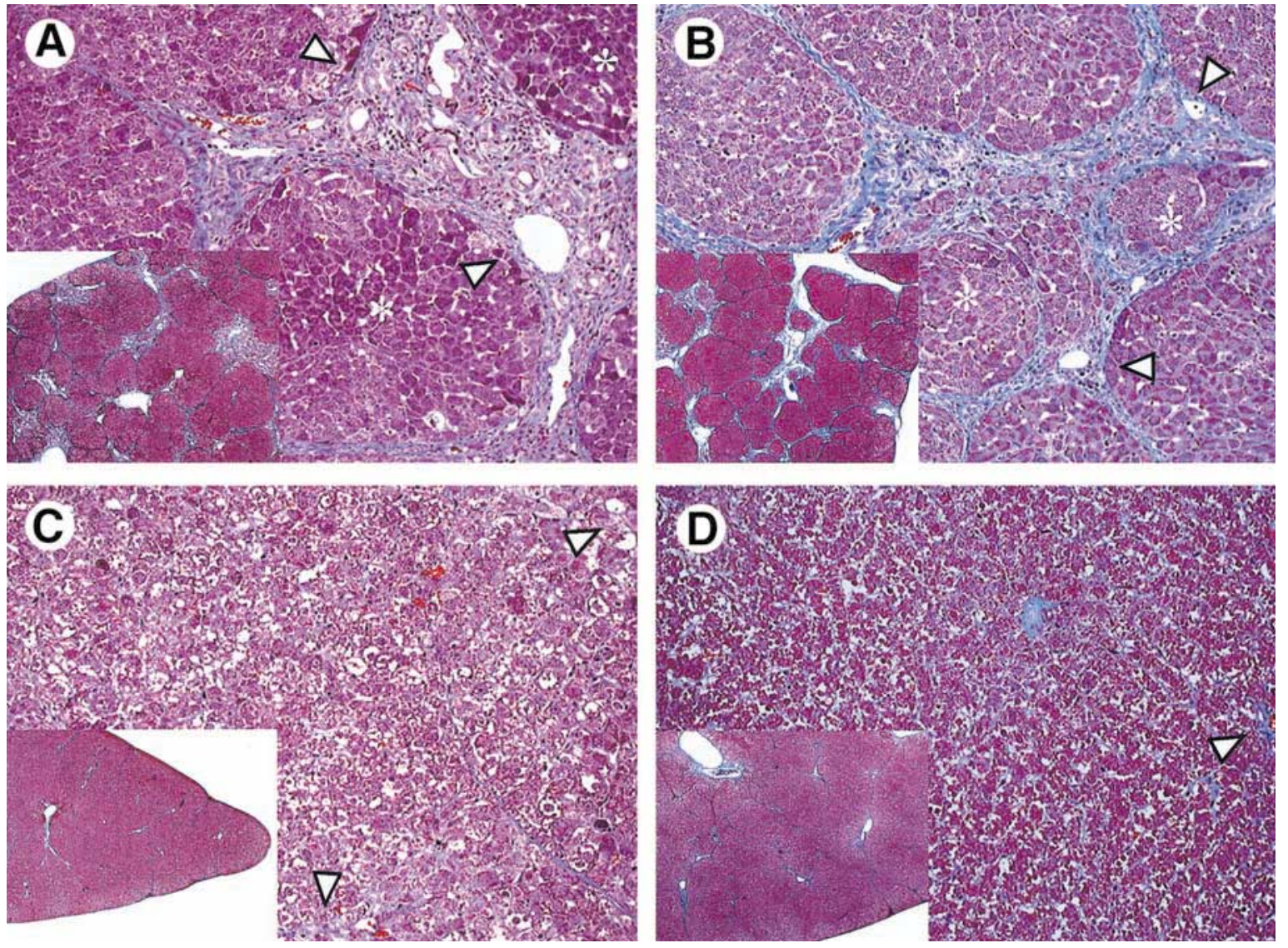

Figure 3. 
white triangles). From these results, we speculated that hepatocyte proliferation was induced by MMP-1 overexpression in the liver independent of adenoviral infection, because the control adenovirus Ad5Lac Z had no effect on histology (Figure 6C). The morphological changes of hepatocytes in Ad5MMP-1-infected rats resolved at 4 weeks after the infection (Figure $6 E$ ). BrdU staining of the TAA-treated liver confirmed the proliferative effect of MMP-1 overexpression (Figure 7). Namely, increased BrdU-positive hepatocytes were observed only in Ad5MMP-1-infected (5\% $\pm 2.6 \%$ ) (Figure $7 B$ ), but not in uninfected or Ad5LacZ-infected, rats at 2 weeks $(0.2 \%$ $\pm 0.1 \%$ and $0.3 \% \pm 0.2 \%$, respectively) (Figure $7 \mathrm{~A}$ and $C)$. However, the positive cells in the Ad5MMP-1treated liver almost disappeared by 4 weeks $(1.0 \% \pm$ $0.3 \%$; Figure $7 D$ ), consistent with the normalization of hepatocyte morphology in $\mathrm{H} \& \mathrm{E}$ staining at 4 weeks (Figure 6E).

At both time points after TAA treatment ( 4 and 7 weeks), dry liver weight in Ad5MMP-1-infected rats significantly increased at 2 weeks compared with that in Ad5LacZ-infected and uninfected rats $(P<0.01)$ (Figure 8). The increased dry liver weight in Ad5MMP-1-treated rats tended to decrease by 4 weeks after infection, although a significant increase in the weight compared with that in Ad5LacZ-treated rats persisted in the 7-week TAA model (Figure 8). Thus, the proliferative effect on hepatocytes by MMP-1 that was observed at 2 weeks gradually disappeared by 4 weeks after the infection.

\section{MMP-1 Expression in the Liver Induced Transient Liver Injury}

Measurement of the liver-specific enzyme ALT in the serum of the rats showed that MMP-1 expression in the liver transiently induced a significant increase in serum ALT $(<200 \mathrm{IU} / \mathrm{L} ; P<0.05)$, which returned to almost normal by 4 weeks after infection (Figure 9). These data imply that the expression of MMP-1 also causes moderate hepatocyte cell damage. However, serum total bilirubin did not change significantly even after the TAA treatment and adenoviral infections in this study (TAA only, $0.13 \pm$ $0.06 \mathrm{mg} / \mathrm{dL}$; TAA plus Ad5MMP-1, $0.25 \pm 0.06 \mathrm{mg} /$ $\mathrm{dL}$; and TAA plus Ad5LacZ, $0.13 \pm 0.05 \mathrm{mg} / \mathrm{dL}$, respectively). Serum albumin levels at death were also not significantly different even after adenoviral treatment (TAA only, $3.77 \pm 0.35 \mathrm{mg} / \mathrm{dL}$; TAA plus Ad5MMP-1, $4.00 \pm 0.22 \mathrm{mg} / \mathrm{dL}$; and TAA plus Ad5LacZ, $4.13 \pm$ $0.24 \mathrm{mg} / \mathrm{dL}$, respectively). From these results, we could conclude that TAA treatment induced stable fibrosis without causing severe liver failure.

\section{Discussion}

Advanced liver fibrosis and cirrhosis are believed to form irreversible scars, characterized by increased deposition and altered composition of ECM. The only curative treatment of end-stage cirrhosis is transplantation, which is limited by the number of donor organs. Several approaches have successfully prevented the progression of liver fibrosis in animal models. ${ }^{15-21}$ However, because fibrotic liver disease may not present clinically until an advanced or cirrhotic stage, the possibility of reversing established fibrosis is an essential issue. Some investigators have reported improvement in liver fibrosis and cirrhosis in selective patients with effective antiviral therapies in chronic viral hepatitis ${ }^{14,36}$ and with surgical decompression of secondary biliary fibrosis, ${ }^{37}$ suggesting a capacity for recovery even from established cirrhosis.

We efficiently delivered to the liver a recombinant adenovirus expressing human pro-MMP-1 that was converted to the active form in situ with functional collagenase activity (Figure $1 C$ and $D$ ) and degraded type I collagen to produce a small fragment (Figure $1 D$ ). We did not analyze the mechanism for conversion of proMMP-1 to the active form in this study. However, plasmin generated from plasminogen by plasminogen activator (uPA) possibly plays an important role in this mechanism. ${ }^{38}$ Although rats do not normally express MMP-1, we used human MMP-1 so that we could begin to access its therapeutic effectiveness for human cirrhosis.

Figure 2. Liver fibrosis induced by thioacetamide (TAA) in the rat is persistent. Liver tissues were stained with Masson's trichrome after treatment with TAA $(200 \mathrm{mg} / \mathrm{kg})$ for 4 weeks $(A$ and $B)$ or 7 weeks $(C$ and $D)$. Livers were collected from rats 3 weeks $(A$ and $C)$ or 5 weeks $(B$ and $D$ ) after the withdrawal of TAA treatment. Mild $(A)$ or advanced $(C)$ liver fibrosis observed at 3 weeks after the withdrawal of TAA did not spontaneously recover by the end of this experiment $(B$ and $D)$. Each figure was a representative picture of 6 individual animals in each group. White triangles indicate portal areas, and asterisks represent pseudo- or regenerating lobules. Original magnification was $200 \times$. Magnification of the inset $(C$ and $D)$ was $20 \times$.

Figure 3. Expression of human MMP-1 in the liver dramatically attenuated established fibrosis. Liver tissues treated with TAA (200 mg/kg) for 7 weeks were stained with Masson's trichrome at $2(A$ and $C)$ or $4(B$ and $D)$ weeks after the adenoviral infections. Liver tissues were collected from Ad5LacZ-infected $(A$ and $B$ ) or Ad5MMP-1 infected $(C$ and $D)$ rats. Ad5LacZ infection had no effect on TAA-induced liver fibrosis, whereas expression of MMP-1 attenuated liver fibrosis at 2 weeks $(C)$, and the attenuated fibrosis remained for 4 weeks $(D)$. Each figure was a representative picture of 6 individual animals in each group. White triangles indicate portal areas, and asterisks represent pseudo- or regenerating lobules. Original magnification was $200 \times$. Magnification of the inset $(C$ and $D)$ was $20 \times$. 


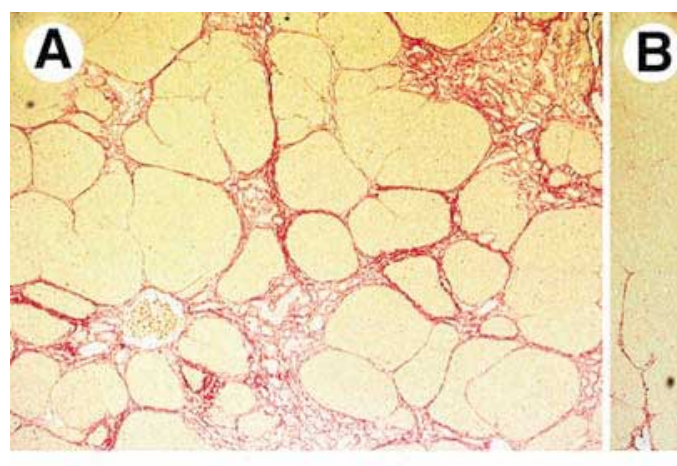

D

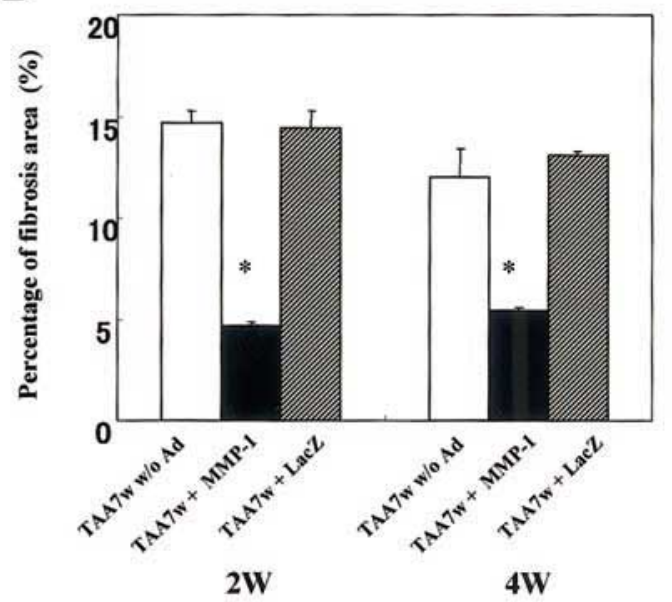

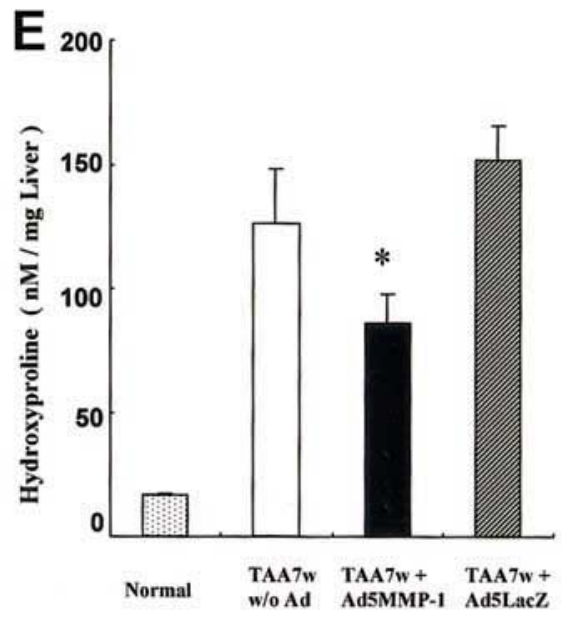

Figure 4.
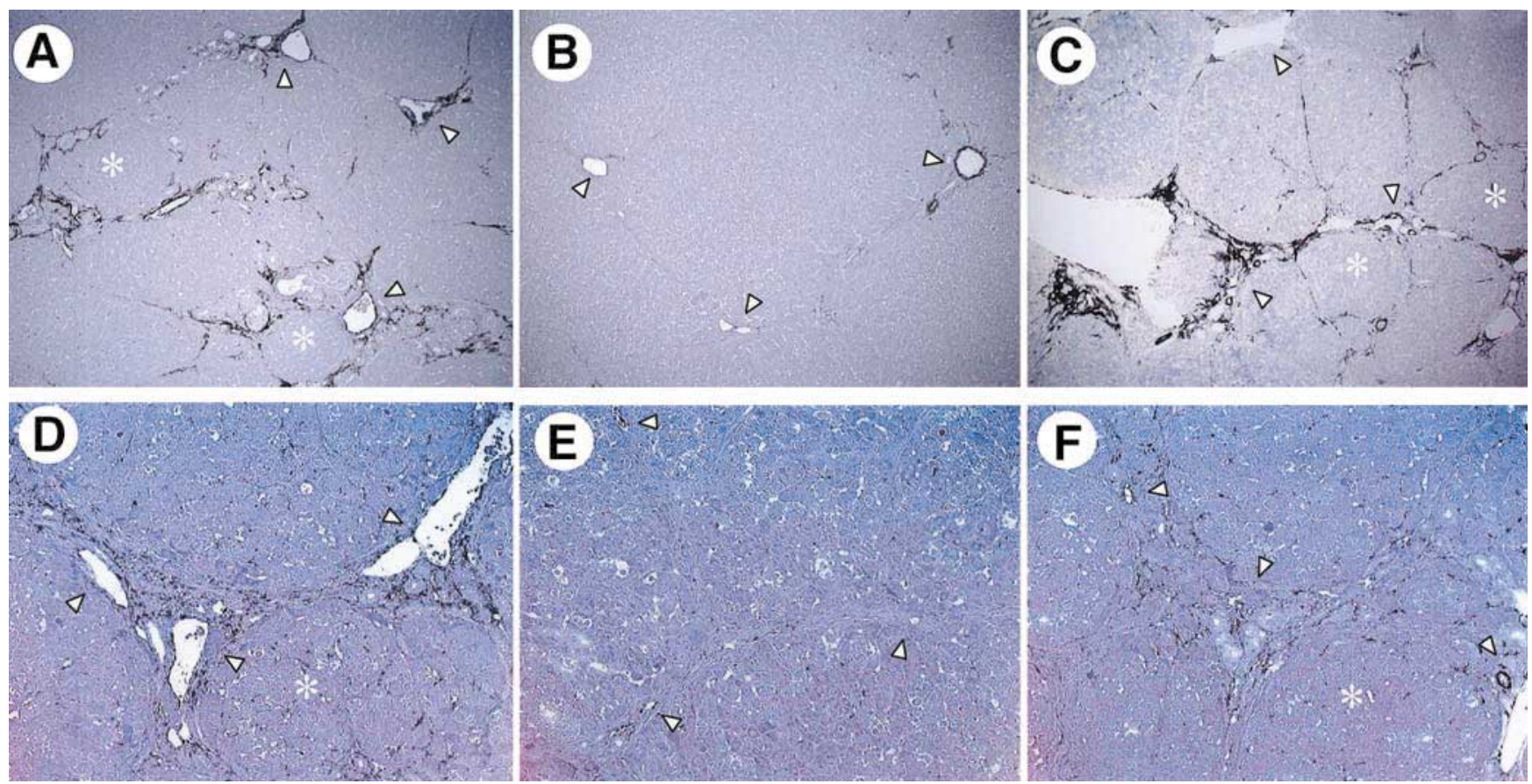

Figure 5. 


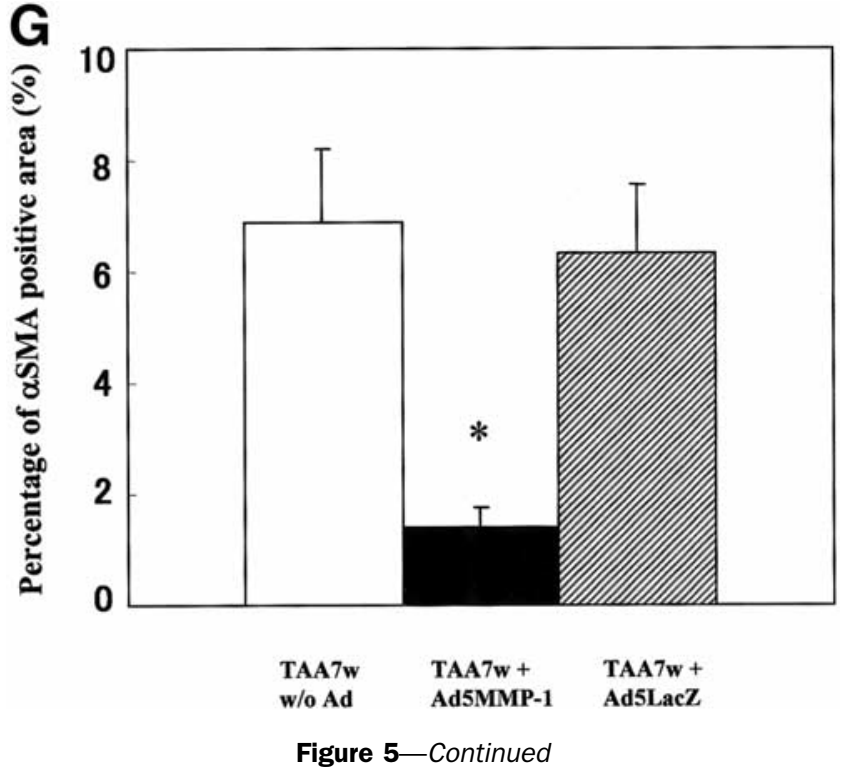

However, because we only gave a single dose of either virus (Ad5MMP-1 or Ad5LacZ), we did not expect an anamnestic response as in a rechallenge experiment. ${ }^{39}$ Recent studies from our laboratory ${ }^{40}$ and others ${ }^{41}$ have also used a single dose of an adenovirus to successfully deliver a therapeutic protein to the liver, although the possibility still remains that differences in the immunogenicity of bacterial $\beta$-galactosidase and delivered proteins could affect the results.

Type I collagen consists of 3 polypeptide chains, each with a molecular mass of approximately 95 kilodaltons, which self-associate into a triple-helical structure. MMP-1 is able to cleave all 3 chains of type I collagen at a single locus between $1 \mathrm{Gly}$-Ile in each $\alpha 1$ chain and 1 Gly-Leu in the $\alpha 2$ chain, ${ }^{42}$ and the fragments generated are melted below $37^{\circ} \mathrm{C} .{ }^{43}$ In our study, established collagen fibers in the liver were dramatically reduced by MMP-1 expression without major inflammation (Figure
4), indicating that the MMP-1 was enzymatically active but did not cause severe hepatic injury. The histological data on the fibrotic response (Figure $4 A-D$ ) seemed much more striking than the quantitative data on hydroxyproline content (Figure $4 E$ ) in this study. This discrepancy between morphometric analysis and quantitative hydroxyproline analysis has also been reported in some previous studies. ${ }^{22,34,35}$ One possible explanation is that some of the degraded collagen fragments will still be in the liver and will be measured as hydroxyproline. Although apparent histological change was observed in the liver, as shown in Figures 3 and 6, no obvious injury in other organs-such as lung, kidney, spleen, heart, and blood vessels - was detected in this study (data not shown). One possible explanation is that secreted proMMP-1 is gradually converted to the active form in situ, as indicated by Western blot (Figure $1 C$ ), and degrades collagens in the liver, whereas any MMP-1 that overflowed out of the liver binds its inhibitor, TIMP. Moreover, Western blot with homogenates from those organs showed no significant expression of MMP-1 (data not shown). Our results are consistent with our underlying hypothesis that failure to resolve the fibrous scar in advanced liver fibrosis results from the imbalance between too few interstitial collagenases and too much ECM and too many TIMPs.

In addition to the reduction of collagen fibers in the liver, we observed fewer activated HSCs after MMP-1 expression (Figure $5 B$ and $G$ ). Fewer activated HSCs during spontaneous resolution of an experimental liver fibrosis have been reported, ${ }^{44}$ and apoptosis of HSCs was proposed as the mechanism. Because the number of desmin-positive cells was also decreased in Ad5MMP-1 rats in our study (Figure $5 E$ ), activated HSCs were not transformed to their quiescent forms, but rather disappeared. HSCs have several integrins on their surface, including $\alpha 1 \beta 1, \alpha 2 \beta 1, \alpha v \beta 1, \alpha 5 \beta 1$, and $\alpha 6 \beta 4 .{ }^{45,46}$

Figure 4. Hepatic collagen content was significantly reduced by Ad5MMP-1 infection. Liver tissues treated with TAA ( $200 \mathrm{mg} / \mathrm{kg}$ ) for 7 weeks were stained with Sirius red at 2 weeks after Ad5MMP-1 $(B)$ or Ad5LacZ $(C)$ infection, or without infection $(A)$, as described in Methods. Collagen fibers are represented as a red area. Each figure was a representative picture of 6 individual animals in each group. Image analysis of the area in the liver, which was performed as described in Methods, showed a significant decrease in the area only in Ad5MMP-1-infected rats at 2 and 4 weeks after infection $(D)(P<0.01)$. Quantitative measurement of hydroxyproline in the liver at 2 weeks showed a significant decrease only in the Ad5MMP-1-infected rats $(E)$. Six animals were examined in each experimental group. The original magnification for Sirius red staining was $40 \times . * P<0.05$ compared with uninfected or Ad5LacZ-infected livers.

Figure 5. The number of activated hepatic stellate cells in the liver was reduced by MMP-1 gene delivery. Immunostaining for $\alpha$-smooth muscle actin ( $\alpha$-SMA) $(A-C)$ and desmin $(D-E)$ was performed in the liver from rats treated with TAA $(200 \mathrm{mg} / \mathrm{kg})$ for 7 weeks. $(A$ and $D)$ Uninfected, $(B$ and $E$ ) Ad5MMP-1-infected, or $(C$ and $F$ ) Ad5LacZ-infected livers at 2 weeks after the infection are shown. An increased number of $\alpha$-SMA-positive cells were observed in uninfected $(A)$ or Ad5LacZ-infected $(C)$ livers, whereas only a few $\alpha$-SMA-positive cells were detected in Ad5MMP-1-infected liver, except for smooth muscle cells in blood vessels $(B)$. The number of desmin-positive cells was also decreased only in Ad5MMP-1-infected livers $(E)$. Each figure was a representative picture of 6 individual animals in each group. White triangles indicate portal areas, and asterisks represent pseudo- or regenerating lobules. The original magnification was $100 \times(A-C)$ or $200 \times(D-F)$. The $\alpha$-SMA-positive area was also semiquantified by image analysis with $\mathrm{NIH}$ Image 1.61, and a significant decrease was detected only in Ad5MMP-1-infected rats (G). Six animals were examined in each experimental group. 

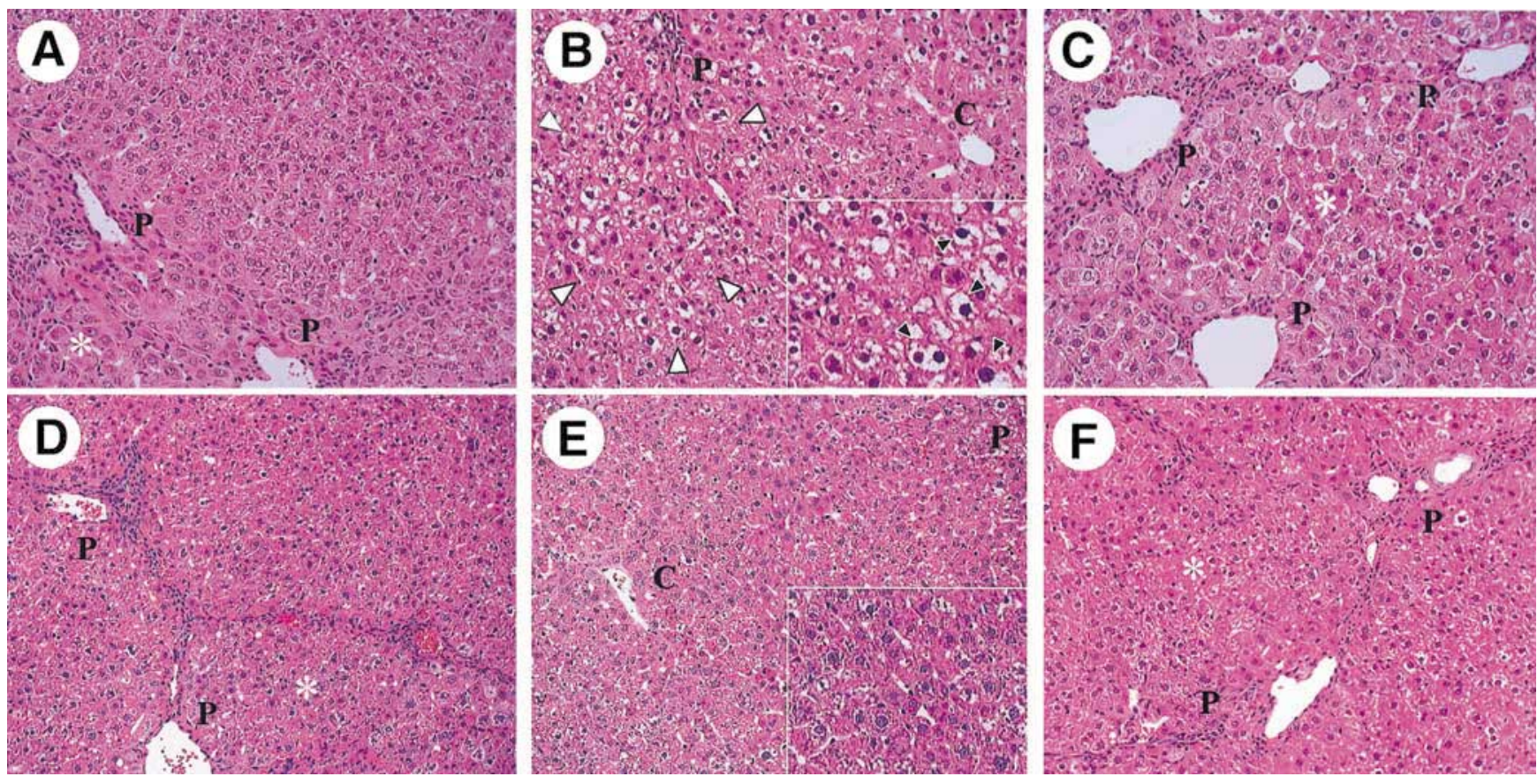

Figure 6.
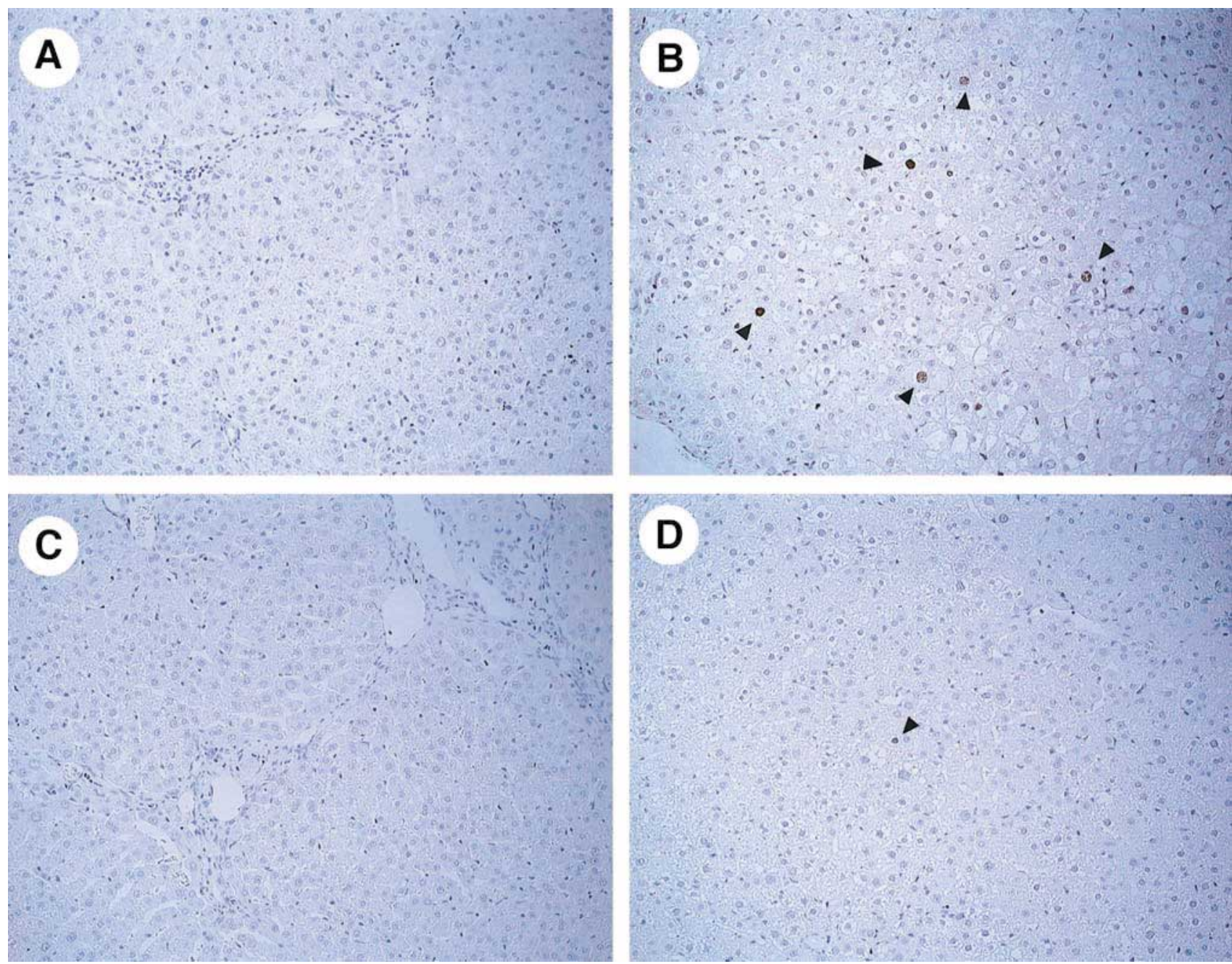

\section{D}

Figure 7. 
TAA 4 weeks

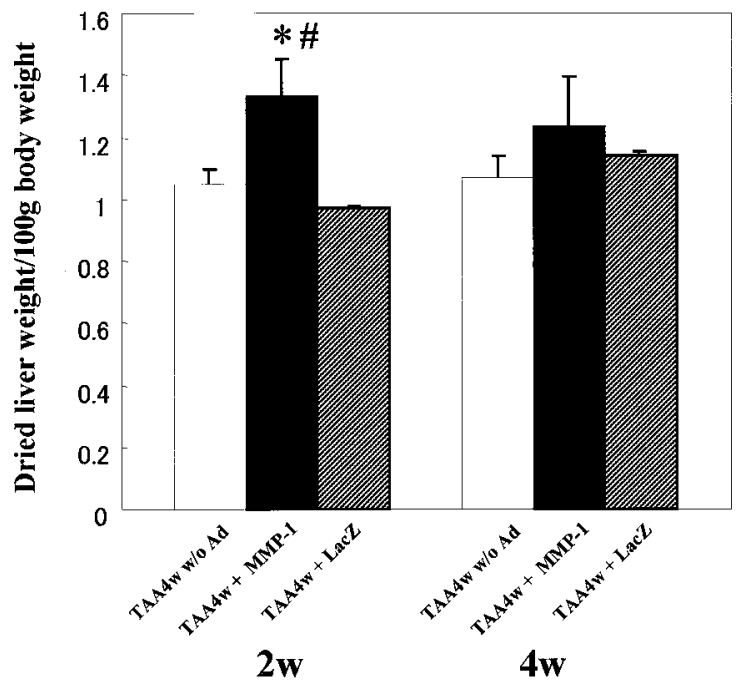

TAA 7 weeks

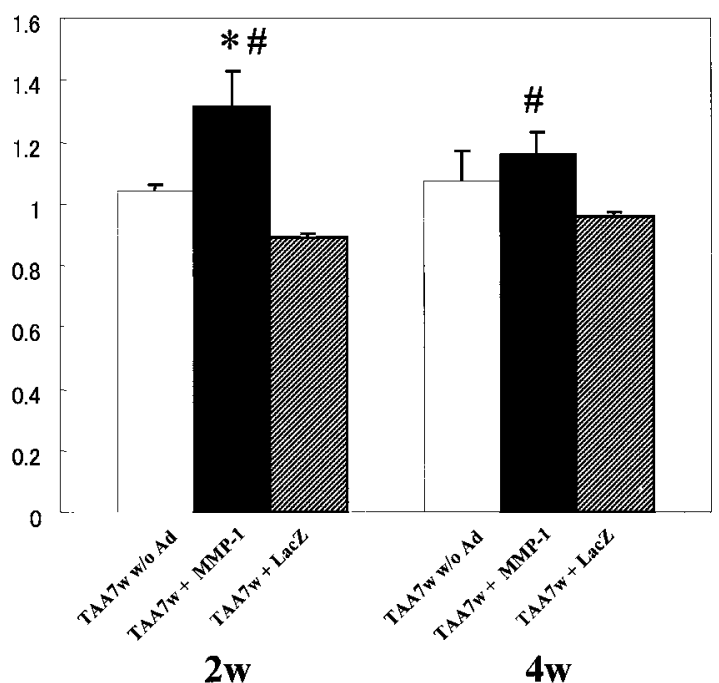

Figure 8. Dry liver weight was significantly increased after Ad5MMP-1 infection. Dry liver weight in uninfected (white bars), Ad5MMP-1-infected (black bars), and Ad5LacZ-infected (hatched bars) groups was determined at 2 or 4 weeks after the adenoviral infection, as described in Methods. Six animals were examined in each experimental group. $* P<0.05$ compared with uninfected control animals. $\# P<0.05$ compared with Ad5LacZ-infected animals.

Among them, major integrins for native collagen type I are $\alpha 1 \beta 1$ and $\alpha 2 \beta 1 .{ }^{47,48}$ Moreover, activated HSCs also have the nonintegrin collagen receptor, discoidin domain receptor-2. ${ }^{3}$ Previous in vitro studies have reported that HSCs are activated on collagen type I, whereas they are quiescent on Matrigel (BD Biosciences, San Jose, CA). ${ }^{49}$ Because native collagen I is degraded by MMP-1 and removed from the liver in our model, activation of HSCs could be attenuated according to detachment from native collagen I. Although we did not investigate whether apoptosis of HSCs occurred, we noted that MMP-1 expression produced a marked decrease in both total and activated HSCs. Thus, we speculate that reducing native collagen type I in vivo by MMP-1 expression could eliminate the activated HSCs by apoptosis.

Another key observation in this study was that proliferation of hepatocytes was induced by MMP-1 expression in the liver. The proliferative effect on hepatocytes was still obvious at 2 weeks after the adenoviral infection (Figures $6 B$ and $7 B$ ) but had almost disappeared by 4 weeks (Figures $6 E$ and $7 D$ ). Toxicity of the viral proteins is of concern with these first-generation adenoviral vectors, including the induction of immune responses. ${ }^{50,51}$ In this study, 2 different control groups were consistently used: non-viral-infected and control Ad5LacZinfected animals. Using these control groups in the experiments, we were able to minimize the adenoviral effect and differentiate it from the MMP-1 effect. Moreover, this proliferation is not specific to the fibrotic liver, because we have observed the same proliferative effect of MMP-1 on hepatocytes when MMP-1 was expressed in normal rat liver (T. Nishio and Y. Iimuro, unpublished observations). When we delivered human MMP-1 and LacZ genes to normal rat liver by using the same adenoviral vectors, we observed hepatocyte proliferation only in Ad5MMP-1-infected, but not in Ad5LacZ-infected, rats. Proliferation of hepatocytes started around 24 hours and had almost stopped by 1 week, accompanied by cytoplasmic accumulation of $\beta$-catenin and a transient decrease in the protein expression of focal adhesion kinase and integrin-linked kinase (data not shown). We also detected a transient increase in serum ALT levels after

Figure 6. MMP-1 expression induced morphological change in hepatocytes. After TAA treatment, uninfected $(A$ and $D)$, Ad5MMP-1-infected $(B$ and $E)$, or Ad5LacZ-infected $(C$ and $F$ ) livers were stained with $\mathrm{H} \& \mathrm{E}$ at 2 weeks $(A-C)$ or 4 weeks $(D-F)$ after infection. In addition to reduced fibrosis, morphological changes in hepatocytes, such as disarrangement of the hepatic trabecula ( $B$; white triangles) and heterogeneity in the size of hepatocytes ( $B$, inset; black triangles), were detected predominantly around the portal vein area (P) only in Ad5MMP-1-infected rats at 2 weeks $(B)$. The morphological change, however, almost disappeared by 4 weeks after the infection $(E)$. Each figure was a representative picture of 6 individual animals in each group. The original magnification was $200 \times$, or $400 \times$ for the insets. $C$, central vein.

Figure 7. DNA synthesis was detected in hepatocytes at 2 weeks after MMP-1 infection. $(A)$ Uninfected, $(B)$ Ad5MMP-1-infected, or $(C)$ Ad5LacZ-infected livers underwent BrdU staining at 2 weeks after infection to detect cells newly synthesizing DNA, as described in Methods. Only in Ad5MMP-1-infected liver were $5 \% \pm 2.6 \%$ of hepatocytes positive for BrdU at 2 weeks $(B)$. This DNA synthesis observed in Ad5MMP-1-infected liver at 2 weeks almost disappeared at 4 weeks after infection $(D)$. Each figure was a representative picture of 6 individual animals in each group. 

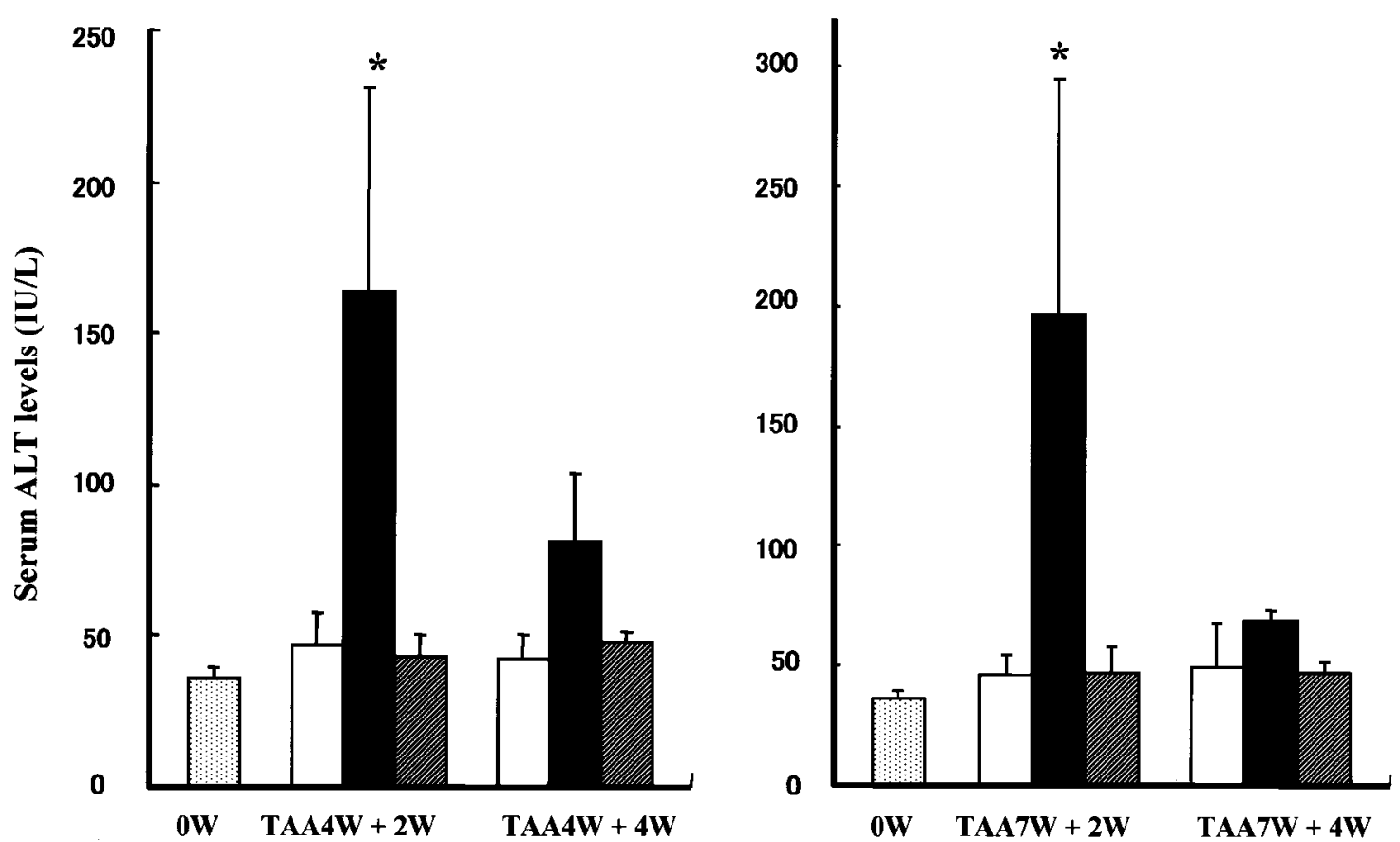

Figure 9. Effect of TAA treatment and adenoviral infections on serum ALT levels. Samples were collected from each animal at death, and serum ALT levels were automatically determined by enzymatic analysis. Six animals were examined in each experimental group. $* P<0.05$ compared with uninfected or Ad5LacZ-infected animals.

MMP-1 expression; these started to increase around 96 hours, peaked around 1 week, and returned to normal levels by 2 weeks. Thus, MMP-1 produced hepatocyte proliferation followed by moderate cellular damage. Other investigators have reported a similar phenomenon in the skin. ${ }^{52}$ They examined the effect of MMP-1 overexpression in the skin by using a series of transgenic mice, in which the human tissue collagenase gene was expressed in the suprabasal layer of the skin epidermis. The skin showed hyperproliferative changes, such as acanthosis, hyperkeratosis, and epidermal hyperplasia, but no obvious inflammation was observed. However, overexpression of TIMP-1 in the liver has been reported to block neoplastic proliferation of liver tumors. ${ }^{53,54}$

However, the molecular mechanisms for the proliferative effect of MMP-1 overexpression still remain elusive. In a previous report, ${ }^{55}$ prominent hepatocyte proliferation was induced by intraportal infusion of collagenase, followed by a treatment with hepatocyte growth factor. Therefore, it is possible in our model that several growth factors bound to hepatic ECM, such as hepatocyte growth factor, ${ }^{56}$ are freed from ECM by MMP-1 and that the activated growth factors facilitate hepatocyte proliferation. Alternatively, changes in interaction between ECM and hepatocyte possibly stimulate hepatocyte proliferation directly because hepatocytes are known to be responsive to the biophysical state of ECM. ${ }^{57}$
Despite the beneficial effects of MMP-1, including attenuation of established liver fibrosis and stimulation of hepatocyte proliferation, its expression also caused mild liver injury, indicated by a transient increase in serum ALT levels (Figure 9). We have less insight into the mechanism by which MMP-1 expression caused liver damage. Apoptosis should not be a major reason for this phenomenon, because we detected only a few apoptotic bodies in the liver by $\mathrm{H} \& \mathrm{E}$ staining even at 2 weeks after Ad5MMP-1 infection. Direct damage to the hepatocyte cell membrane because of prolonged exposure to an active form of MMP-1 possibly participates in the mechanism, although major inflammation due to hepatocyte necrosis was not detected. Although uninfected and control adenoviral-infected rats did not have this transient liver injury, we cannot exclude the possibility that this structural reorganization was induced independently of collagenase activity.

In conclusion, we shifted the balance between profibrogenesis (ECM and TIMPs) and antifibrogenesis (collagenases) in a model of stable hepatic fibrosis. Transient expression of human pro-MMP-1 in the liver diminished established hepatic fibrosis without major hepatic injury or inflammation, despite a transient increase in serum ALT levels. Although prolonged MMP-1 expression in transgenic animals may have a carcinogenic effect, ${ }^{52}$ gene transfer with an adenoviral vector is limited, and mor- 
phological changes in hepatocytes returned to almost normal by 4 weeks (Figure $6 B$ versus $6 E$ ). Thus, both collagen degradation and transient cellular damage mediated by active MMP-1 may be beneficial to the remarkable resolution of stable fibrosis.

\section{References}

1. Schuppan D, Cho JJ, Jia JD, Hahn EG. Interplay of matrix and myofibroblasts during hepatic fibrogenesis. Curr Top Pathol 1999;93:205-218.

2. Brenner DA, Waterboer T, Choi SK, Lindquist JN, Stefanovic B, Burchardt E, Yamauchi M, Gillan A, Rippe RA. New aspects of hepatic fibrosis. J Hepatol 2000;32:32-38.

3. Friedman SL. Molecular regulation of hepatic fibrosis, an integrated cellular response to tissue injury. J Biol Chem 2000;275: 2247-2250.

4. Freije JM, Diez-Itza I, Balbin M, Sanchez LM, Blasco R, Tolivia J, Lopez-Otin C. Molecular cloning and expression of collagenase-3, a novel human matrix metalloproteinase produced by breast carcinomas. J Biol Chem 1994;269:16766-16773.

5. Emonard H, Grimaud JA. Matrix metalloproteinases. A review. Cell Mol Biol 1990;36:131-153.

6. Preaux AM, Mallat A, Nhieu JT, D'Ortho MP, Hembry RM, Mavier P. Matrix metalloproteinase-2 activation in human hepatic fibrosis regulation by cell-matrix interactions. Hepatology 1999;30: 944-950.

7. Milani S, Herbst H, Schuppan D, Grappone C, Pellegrini G, Pinzani M, Casini A, Calabro A, Ciancio G, Stefanini F. Differential expression of matrix-metalloproteinase-1 and -2 genes in normal and fibrotic human liver. Am J Pathol 1994;144:528-537.

8. Kossakowska AE, Edwards DR, Lee SS, Urbanski LS, Stabbler AL, Zhang CL, Phillips BW, Zhang Y, Urbanski SJ. Altered balance between matrix metalloproteinases and their inhibitors in experimental biliary fibrosis. Am J Pathol 1998;153:1895-1902.

9. Iredale JP, Murphy G, Hembry RM, Friedman SL, Arthur MJ. Human hepatic lipocytes synthesize tissue inhibitor of metalloproteinases-1. Implications for regulation of matrix degradation in liver. J Clin Invest 1992;90:282-287.

10. Murawaki $Y$, Yamamoto $H$, Kawasaki $H$, Shima $H$. Serum tissue inhibitor of metalloproteinases in patients with chronic liver disease and with hepatocellular carcinoma. Clin Chim Acta 1993; 218:47-58.

11. Leyland H, Gentry J, Arthur MJ, Benyon RC. The plasminogenactivating system in hepatic stellate cells. Hepatology 1996;24: 1172-1178.

12. Zhang LP, Takahara T, Yata Y, Furui K, Jin B, Kawada N, Watanabe A. Increased expression of plasminogen activator and plasminogen activator inhibitor during liver fibrogenesis of rats: role of stellate cells. J Hepatol 1999;31:703-711.

13. Leiper K, Croll A, Booth NA, Moore NR, Sinclair T, Bennett B. Tissue plasminogen activator, plasminogen activator inhibitors, and activator-inhibitor complex in liver disease. J Clin Pathol 1994;47:214-217.

14. Dufour JF, DeLellis R, Kaplan MM. Regression of hepatic fibrosis in hepatitis $C$ with long-term interferon treatment. Dig Dis Sci 1998;43:2573-2576.

15. Yasuda M, Shimizu I, Shiba M, Ito S. Suppressive effects of estradiol on dimethylnitrosamine-induced fibrosis of the liver in rats. Hepatology 1999;29:719-727.

16. Ueno H, Sakamoto T, Nakamura T, Qi Z, Astuchi N, Takeshita A, Shimizu K, Ohashi H. A soluble transforming growth factor beta receptor expressed in muscle prevents liver fibrogenesis and dysfunction in rats. Hum Gene Ther 2000;11:33-42.

17. Zhu J, Wu J, Frizell E, Liu SL, Bashey R, Rubin R, Norton P, Zern MA. Rapamycin inhibits hepatic stellate cell proliferation in vitro and limits fibrogenesis in an in vivo model of liver fibrosis. Gastroenterology 1999;117:1198-1204.

18. Qi Z, Atsuchi N, Ooshima A, Takeshita A, Ueno H. Blockade of type beta transforming growth factor signaling prevents liver fibrosis and dysfunction in the rat. Proc Natl Acad Sci U S A 1999;96:2345-2349.

19. Masunaga H, Fujise N, Shiota A, Ogawa H, Sato Y, Imai E, Yasuda $\mathrm{H}$, Higashio K. Preventive effects of the deleted form of hepatocyte growth factor against various liver injuries. Eur J Pharmacol 1998;342:267-279.

20. Murata T, Arii S, Nakamura T, Mori A, Kaido T, Furuyama H, Furumoto K, Nakao T, Isobe N, Imamura M. Inhibitory effect of Y-27632, a ROCK inhibitor, on progression of rat liver fibrosis in association with inactivation of hepatic stellate cells. J Hepatol 2001;35:474-481.

21. Tada S, Iwamoto H, Nakamuta M, Sugimoto R, Enjoji M, Nakashima Y, Nawata H. A selective ROCK inhibitor, Y27632, prevents dimethylnitrosamine-induced hepatic fibrosis in rats. J Hepatol 2001;34:529-536.

22. Matsuda $\mathrm{Y}$, Matsumoto $\mathrm{K}$, Yamada A, Ichida $T$, Asakura $H$, Komoriya Y, Nishiyama E, Nakamura T. Preventive and therapeutic effects in rats of hepatocyte growth factor infusion on liver fibrosis/cirrhosis. Hepatology 1997;26:81-89.

23. Ueki T, Kaneda Y, Tsutsui H, Nakanishi K, Sawa Y, Morishita R, Matsumoto K, Nakamura T, Takahashi H, Okamoto E, Fujimoto $J$. Hepatocyte growth factor gene therapy of liver cirrhosis in rats. Nat Med 1999;5:226-230.

24. Bett AJ, Haddara W, Prevec L, Graham FL. An efficient and flexible system for construction of adenovirus vectors with insertions or deletions in early regions 1 and 3. Proc Natl Acad Sci U S A 1994;91:8802-8806.

25. Angel P, Baumann I, Stein B, Delius H, Rahmsdorf HJ, Herrlich P. 12-O-Tetradecanoyl-phorbol-13-acetate induction of the human collagenase gene is mediated by an inducible enhancer element located in the $5^{\prime}$-flanking region. Mol Cell Biol 1987;7:22562266.

26. Diehl AM, Yin M, Fleckenstein J, Yang SQ, Lin HZ, Brenner DA, Westwick J, Bagby G, Nelson S. Tumor necrosis factor-alpha induces c-jun during the regenerative response to liver injury. Am J Physiol 1994;267:G552-G561.

27. Okazaki I, Maruyama K. Collagenase activity in experimental hepatic fibrosis. Nature 1974;252:49-50.

28. Miyahara T, Schrum L, Rippe R, Xiong S, Yee HF Jr, Motomura K, Anania FA, Willson TM, Tsukamoto H. Peroxisome proliferatoractivated receptors and hepatic stellate cell activation. J Biol Chem 2000;275:35715-35722.

29. Muller A, Machnik F, Zimmermann T, Schubert H. Thioacetamideinduced cirrhosis-like liver lesions in rats-usefulness and reliability of this animal model. Exp Pathol 1988;34:229-236.

30. Oren R, Dotan I, Papa M, Marravi Y, Aeed H, Barg J, Zeidel L, Bruck R, Halpern Z. Inhibition of experimentally induced cirrhosis in rats by hypothyroidism. Hepatology 1996;24:419-423.

31. MacGregor GR, Mogg AE, Burke JF, Caskey CT. Histochemical staining of clonal mammalian cell lines expressing $\mathrm{E}$. coli beta galactosidase indicates heterogeneous expression of the bacterial gene. Somat Cell Mol Genet 1987;13:253-265.

32. Lopez-De Leon A, Rojkind M. A simple micromethod for collagen and total protein determination in formalin-fixed paraffin-embedded sections. J Histochem Cytochem 1985;33:737-743.

33. Woessner JFJ. The determination of hydroxyproline in tissue and protein samples containing small proportions of this imino acid. Arch Biochem Biophys 1961;93:440-447.

34. Bickel M, Baringhaus KH, Gerl M, Gunzler V, Kanta J, Schmidts L, Stapf M, Tschank G, Weidmann K, Werner U. Selective inhibition of hepatic collagen accumulation in experimental liver fibrosis in rats by a new prolyl 4-hydroxylase inhibitor. Hepatology 1998;28: 404-411. 
35. Sakaida I, Hironaka K, Uchida K, Suzuki C, Kayano K, Okita K. Fibrosis accelerates the development of enzyme-altered lesions in the rat liver. Hepatology 1998;28:1247-1252.

36. Sobesky R, Mathurin P, Charlotte F, Moussalli J, Olivi M, Vidaud M, Ratziu V, Opolon P, Poynard T. Modeling the impact of interferon alfa treatment on liver fibrosis progression in chronic hepatitis C: a dynamic view. The Multivirc Group. Gastroenterology 1999;116:378-386.

37. Hammel P, Couvelard A, O'Toole D, Ratouis A, Sauvanet A, Flejou JF, Degott C, Belghiti J, Bernades P, Valla D, Ruszniewski P, Levy $P$. Regression of liver fibrosis after biliary drainage in patients with chronic pancreatitis and stenosis of the common bile duct. N Engl J Med 2001;344:418-423.

38. Carmeliet $P$, Moons L, Lijnen R, Baes M, Lemaitre V, Tipping $P$, Drew A, Eeckhout Y, Shapiro S, Lupu F, Collen D. Urokinasegenerated plasmin activates matrix metalloproteinases during aneurysm formation. Nat Genet 1997;17:439-444.

39. Rosati E, Scaringi L, Cornacchione P, Fettucciari K, Sabatini R, Mezzasoma L, Benedetti C, Cianetti S, Rossi R, Marconi P. Activation of cytokine genes during primary and anamnestic immune response to inactivated c. albicans. Immunology 1996;89: 142-151.

40. Lehmann TG, Wheeler MD, Schwabe RF, Connor HD, Schoonhoven R, Bunzendahl H, Brenner DA, Jude Samulski R, Zhong Z, Thurman RG. Gene delivery of $\mathrm{Cu} / \mathrm{Zn}$-superoxide dismutase improves graft function after transplantation of fatty livers in the rat. Hepatology 2000;32:1255-1264.

41. Zwacka RM, Zhou W, Zhang Y, Darby CJ, Dudus L, Halldorson J, Oberley L, Engelhardt JF. Redox gene therapy for ischemia/ reperfusion injury of the liver reduces AP1 and NF-kappaB activation. Nat Med 1998;4:698-704.

42. Highberger JH, Corbett C, Gross J. Isolation and characterization of a peptide containing the site of cleavage of the chick skin collagen alpha $1[1]$ chain by animal collagenases. Biochem Biophys Res Commun 1979;89:202-208.

43. Stark M, Kuhn K. The properties of molecular fragments obtained on treating calfskin collagen with collagenase from Clostridium histolyticum. Eur J Biochem 1968;6:534-541.

44. Iredale JP, Benyon RC, Pickering J, McCullen M, Northrop M, Pawley S, Hovell C, Arthur MJ. Mechanisms of spontaneous resolution of rat liver fibrosis. Hepatic stellate cell apoptosis and reduced hepatic expression of metalloproteinase inhibitors. J Clin Invest 1998;102:538-549.

45. Carloni V, Romanelli RG, Pinzani M, Laffi G, Gentilini P. Expression and function of integrin receptors for collagen and laminin in cultured human hepatic stellate cells. Gastroenterology 1996; 110:1127-1136.

46. Iwamoto H, Sakai H, Kotoh K, Nakamuta M, Nawata H. Soluble Arg-Gly-Asp peptides reduce collagen accumulation in cultured rat hepatic stellate cells. Dig Dis Sci 1999;44:1038-1045.

47. Gullberg D, Gehlsen KR, Turner DC, Ahlen K, Zijenah LS, Barnes MJ, Rubin K. Analysis of alpha 1 beta 1, alpha 2 beta 1 and alpha
3 beta 1 integrins in cell-collagen interactions: identification of conformation dependent alpha 1 beta 1 binding sites in collagen type I. EMBO J 1992;11:3865-3873.

48. Kirchhofer D, Languino LR, Ruoslahti E, Pierschbacher MD. Alpha 2 beta 1 integrins from different cell types show different binding specificities. J Biol Chem 1990;265:615-618.

49. Maher JJ, Bissell DM. Cell-matrix interactions in liver. Semin Cell Biol 1993;4:189-201.

50. Engelhardt JF, Ye X, Doranz B, Wilson JM. Ablation of E2A in recombinant adenoviruses improves transgene persistence and decreases inflammatory response in mouse liver. Proc Natl Acad Sci U S A 1994;91:6196-6200.

51. Gao GP, Yang Y, Wilson JM. Biology of adenovirus vectors with E1 and E4 deletions for liver-directed gene therapy. J Virol 1996;70: 8934-8943.

52. D'Armiento J, DiColandrea T, Dalal SS, Okada Y, Huang MT, Conney $\mathrm{AH}$, Chada $\mathrm{K}$. Collagenase expression in transgenic mouse skin causes hyperkeratosis and acanthosis and increases susceptibility to tumorigenesis. Mol Cell Biol 1995;15: 5732-5739.

53. Martin DC, Fowlkes JL, Babic B, Khokha R. Insulin-like growth factor II signaling in neoplastic proliferation is blocked by transgenic expression of the metalloproteinase inhibitor TIMP-1. J Cell Biol 1999;146:881-892.

54. Martin DC, Sanchez-Sweatman OH, Ho AT, Inderdeo DS, Tsao MS, Khokha R. Transgenic TIMP-1 inhibits simian virus $40 \mathrm{~T}$ antigen-induced hepatocarcinogenesis by impairment of hepatocellular proliferation and tumor angiogenesis. Lab Invest 1999; 79:225-234.

55. Liu ML, Mars WM, Zarnegar R, Michalopoulos GK. Collagenase pretreatment and the mitogenic effects of hepatocyte growth factor and transforming growth factor-alpha in adult rat liver. Hepatology 1994;19:1521-1527.

56. Schuppan D, Schmid M, Somasundaram R, Ackermann R, Ruehl M, Nakamura T, Riecken EO. Collagens in the liver extracellular matrix bind hepatocyte growth factor. Gastroenterology 1998; 114:139-152.

57. Lindblad WJ, Schuetz EG, Redford KS, Guzelian PS. Hepatocellular phenotype in vitro is influenced by biophysical features of the collagenous substratum. Hepatology 1991;13:282-288.

Received July 8, 2002. Accepted October 24, 2002.

Address requests for reprints to: Yuji limuro, M.D., Ph.D., First Department of Surgery, Hyogo College of Medicine, 1-1 Mukogawa-cho, Nishinomiya, Hyogo 663-8501, Japan. e-mail: siimuro@hyo-med.ac.jp; fax: (81) 798-45-6581.

This work was supported by grants-in-aid for Scientific Research (B) (No. 10470256 and 14370394) to Y.I. from the Ministry of Education, Culture, Sports, Science and Technology of Japan and grants from the National Institutes of Health and Bayer Pharmaceutical Company (to D.A.B.). 